\title{
EFFECT OF DRILL STRING ROTATION ON THE DYNAMIC RESPONSE OF DRILLING RISERS
}

\author{
I.E. MAJOR ${ }^{*}$ and A. Big-ALABO \\ Department of Mechanical Engineering \\ University of Port Harcourt \\ Rivers State, NIGERIA \\ E-mail: igoke.major@uniport.edu.ng \\ S. ODI-OWEI \\ Department of Mechanical Engineering \\ Rivers State University of Science and Technology \\ Rivers State, NIGERIA
}

\begin{abstract}
The effect of the rotation of a drill string on the response of a drilling riser has been studied. A governing equation for the flexural response that incorporates the effect of the drill string rotation is developed from first principles, and the resulting differential equation is found to have a variable coefficient, which is a function of the drill string rotational speed. Results simulated for the free vibration response show that the drill string rotation reduces the natural frequency and increases the amplitude of vibration of the drilling riser. The implication of these findings is that neglecting the effect of rotation of the drill string leads to under-estimation of the deflection and over-estimation of the natural frequency. Further analysis reveals that for a drilling riser of given dimensions, a drill string rotational speed exists at which the natural frequency of the drilling riser is theoretical equal to zero, and this rotational speed is the threshold rotational speed.
\end{abstract}

Key words: drilling riser, drill string, drill string rotational speed, free vibration, threshold rotational speed.

\section{Introduction}

As the exploration of underwater crude and gas resources becomes increasingly needful, offshore technology for deep water drilling systems comes into closer focus. The fact that the aim of underwater crude and gas exploration is to access and drill such resources, with the aid of drilling systems, underscores the importance of a drilling riser, which is the direct component of the drilling system by which this is made possible. A drilling marine riser, part of the blowout system, houses the drill bit and drill string. It is designed to be flexible and sturdy enough to withstand any movement from the drilling platform situated above the sea.

The analysis of general risers has a historical span of over half a century, and a lot has been discovered in this area to the extent that it is well established. Charkrabarti and Frampton (1982) have presented a state-of-the-art review of riser analysis, and they developed the governing equation of motion of general risers from first principles. Ghadimi (1988) used the lumped mass discretization method to derive the equations of motion of flexible risers in three-dimensional space. Spanos et al. (1990) developed a model for a marine riser system that is appropriate for the study of its dynamic behaviour in deepwater conditions. The model was used to estimate the steady-state response of the riser to harmonic excitation. Kaewunruen et al. (2005) investigated the nonlinear free vibration of marine risers to determine the nonlinear natural frequencies and their corresponding mode shapes. Based on the virtual work-energy function of marine risers, they developed the structural model from the strain energy due to bending, the virtual works due to

\footnotetext{
" To whom correspondence should be addressed
} 
effective tension and external forces, and the kinetic energies due to the marine riser and the internal motions. Kerber and Wiercigroch (2088) studied the effect of weak structural nonlinearity on the dynamic behaviour of a vertical marine riser subjected to vortex-induced vibration, whereas Chen et al. (2009) reexamined the vibration characteristics of marine risers using the method of the differential transformation.

Some devotion has been given to the study of drilling risers in particular, but all such studies have been mainly focussed on the drill string as can be observed from the following studies: Vaz and Patel (1995), Sampaio et al. (2007), Gulyayev et al. (2009), Gulyayev and Borshch (2011), etc. These studies have treated the drill string as an independent structure whose motion does not influence any other structure or vice versa. This is not always the case in reality as the drill string is housed by the drilling riser to which it is attached at various points along its span. The implication is that the connection between the drilling riser and the drill string is such that there is a negligible relative translational motion between them, but relative rotational motion of the drill string is permitted. The focus of this study is on the response of drilling risers during the production of crudeoil, at which time the drill string is rotating. In this paper, the effect of the rotation of the drill string on the behaviour of the drilling riser has been investigated. First, a modified riser model that applies specifically to the drilling riser was developed, and then the effect of the rotational speed of the drill string on the free vibration response of the drilling riser was examined by means of codes written in Mathematica ${ }^{\mathrm{TM}}$.

\section{Mathematical model for flexural motion of drilling risers}

Starting from first principles as in Chakrabarti and Frampton (1982), the force exerted by the rotation of the drill string, $F_{R} \theta$, on the drilling riser can be represented on the riser segment as shown in Fig.1.

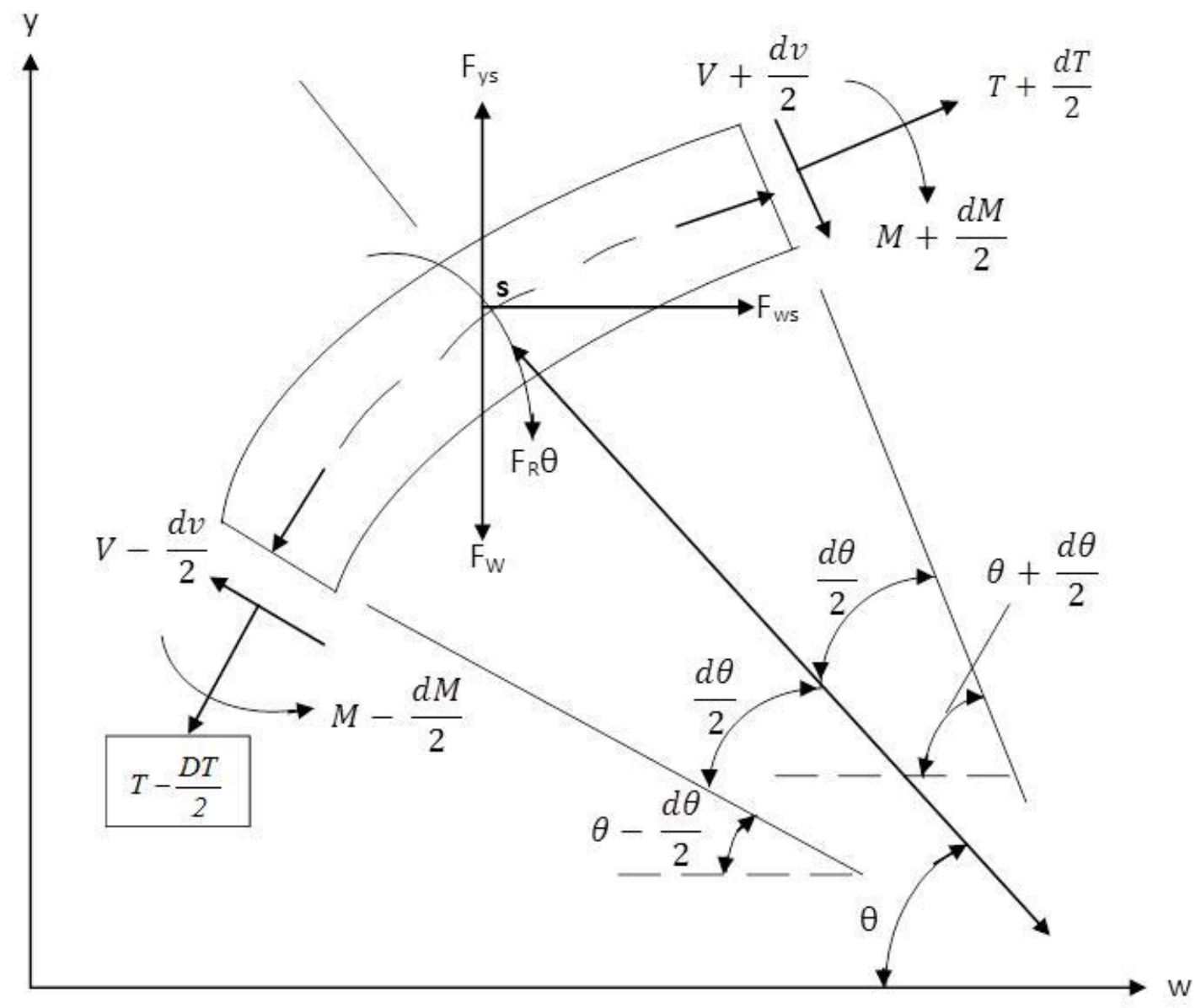

Fig.1. Free body diagram of a bent tubular segment. 
The following mathematical assumptions have been used

(A) The length of the segment is small so that

$$
\cos d \theta \approx 1 \quad \text { and } \quad \sin d \theta \approx d \theta
$$

(B) The small deflection beam theory is applicable. Therefore,

$$
\sin \theta \approx \frac{\partial w}{\partial s} \quad \text { and } \quad \cos \theta \approx \frac{d y}{d s}
$$

(C) The angle of deflection, $\theta$, is small, i.e.,

$$
d s \approx d y, \quad \cos \theta \approx 1, \quad \sin \theta \approx \theta \approx \frac{\partial w}{\partial y} \quad \text { and } \quad \frac{d \theta}{d y} \approx \frac{\partial^{2} w}{\partial y^{2}} .
$$

\subsection{Vertical equilibrium equation}

Considering the equilibrium of vertical forces, we have

$$
\begin{aligned}
& \left(V-\frac{d V}{2}\right) \sin \left(\theta-\frac{d \theta}{2}\right)-\left(V+\frac{d V}{2}\right) \sin \left(\theta+\frac{d \theta}{2}\right)+ \\
& -\left(T-\frac{d T}{2}\right) \cos \left(\theta-\frac{d \theta}{2}\right)+\left(T+\frac{d T}{2}\right) \cos \left(\theta+\frac{d \theta}{2}\right)-F_{W}+F_{y s}=0 .
\end{aligned}
$$

yields

Expanding the double-angle trigonometric ratios in Eq.(2.4) and simplifying the resulting equation

$$
A \cos \theta-B \sin \theta-F_{w}+F_{y s}=0
$$

where

$$
\begin{aligned}
& A=d T \cos \frac{d \theta}{2}-2 V \sin \frac{d \theta}{2}, \\
& B=d V \cos \frac{d \theta}{2}+2 T \sin \frac{d \theta}{2} .
\end{aligned}
$$

\subsection{Horizontal equilibrium equation}

In a similar manner, the equilibrium of horizontal forces would yield

$$
A \sin \theta+B \cos \theta+F_{w s}-m_{w} \ddot{w} d s=0
$$

where $m_{w}=$ mass of the segment including added mass per unit length acting in the $w$ direction; $\ddot{w}=$ acceleration of point $s$ in the $w$-direction. 


\subsection{Moment equilibrium equation}

Taking moments about point $s$ gives the moment equilibrium equation as

$$
d T\left(1-\cos \frac{d \theta}{2}\right)+d M+2 V \sin \frac{d \theta}{2}+\left(F_{R} \cos \frac{d \theta}{2}\right) \theta=0
$$
written as

Considering that the length of the segment is small, Eq.(2.1), the three equilibrium equations can be

$$
\begin{aligned}
& A_{l} \cos \theta-B_{I} \sin \theta-f_{w}+f_{y s}=0, \\
& A_{l} \sin \theta+B_{l} \cos \theta+f_{w s}-m_{w} \ddot{w}=0, \\
& \frac{d M}{d s}+V+F_{R} \theta=0
\end{aligned}
$$

where

$$
\begin{aligned}
& A_{l}=\frac{d T}{d s}-V \frac{d \theta}{d s}, \\
& B_{1}=\frac{d V}{d s}+T \frac{d \theta}{d s}
\end{aligned}
$$

$f_{w}, f_{y s}$ and $f_{w s}$ are the weight and force intensities (i.e., force per unit length).

To develop the equation of motion for the horizontal displacement of the riser, $A_{1}$ in Eq.(2.8a) is substituted into Eq.(2.8b) to get

$$
B_{l} \sec \theta+\left(f_{w}-f_{y s}\right) \tan \theta+f_{w s}-m_{w} \ddot{w}=0 .
$$

By making use of Eqs (2.8c) and (2.9b), the expression for $B_{1}$ is obtained as

$$
B_{I}=\frac{d}{d s}\left[-\frac{d}{d s}\left(E I \frac{d \theta}{d s}\right)-F_{R} \theta\right]+T \frac{d \theta}{d s}
$$

The following expressions are applicable to all risers (Chakrabarti and Frampton, 1982).

$$
\begin{aligned}
& f_{w}=\gamma_{s}\left(A_{o}-A_{i}\right), \\
& f_{w p}=f_{n p} \cos \theta, \quad \text { as part of } \quad f_{w s}, \\
& f_{y p}=-f_{n p} \sin \theta \quad \text { as part of } \quad f_{y s}, \\
& f_{n p}=\left(A_{o} \bar{P}_{o}-A_{i} \bar{P}_{1}\right) \frac{d \theta}{d s}-\left(A_{o} \gamma_{o}-A_{i} \gamma_{i}\right) \sin \theta .
\end{aligned}
$$


Equations (2.11) and (2.12) are substituted into Eq.(2.10) and the equation of motion for horizontal displacement of the marine risers is derived as

$$
\begin{aligned}
& \frac{d^{2}}{d s^{2}}\left(E I \frac{\partial^{2} w}{\partial y^{2}}\right)-\left(T+A_{o} \bar{P}_{o}-F_{R}-A_{i} \bar{P}_{i}\right) \frac{\partial^{2} w}{\partial y^{2}}+ \\
& -\left[\gamma_{s}\left(A_{o}-A_{i}\right)-f_{y s}-A_{o} \gamma_{o}+A_{i} \gamma_{i}\right] \frac{\partial w}{\partial y}+m_{w} \ddot{w}=f_{w s} .
\end{aligned}
$$

In the literature, the effect of the axial force induced by rotation is normally neglected i.e., $F_{R}=0$. This condition is okay for modelling the dynamic response of general risers. However, a special situation occurs with drilling risers where the axial force induced by rotation of the drill string can significantly affect the response of the riser. Then $F_{R}$ cannot be ignored and the expression for determining this force is considered next.

A detailed derivation of the axial force induced by a rotating hollow cylindrical shaft can be found in Behzad and Bastami (2004). They expressed this force as

$$
F=\rho v I_{p} \Omega^{2}
$$

where $I_{p}=\pi\left(b^{4}-a^{4}\right) / 2$ is the moment of inertia of the shaft and $\Omega$ is the rotational speed of the shaft in $\mathrm{rev} / \mathrm{min}$.

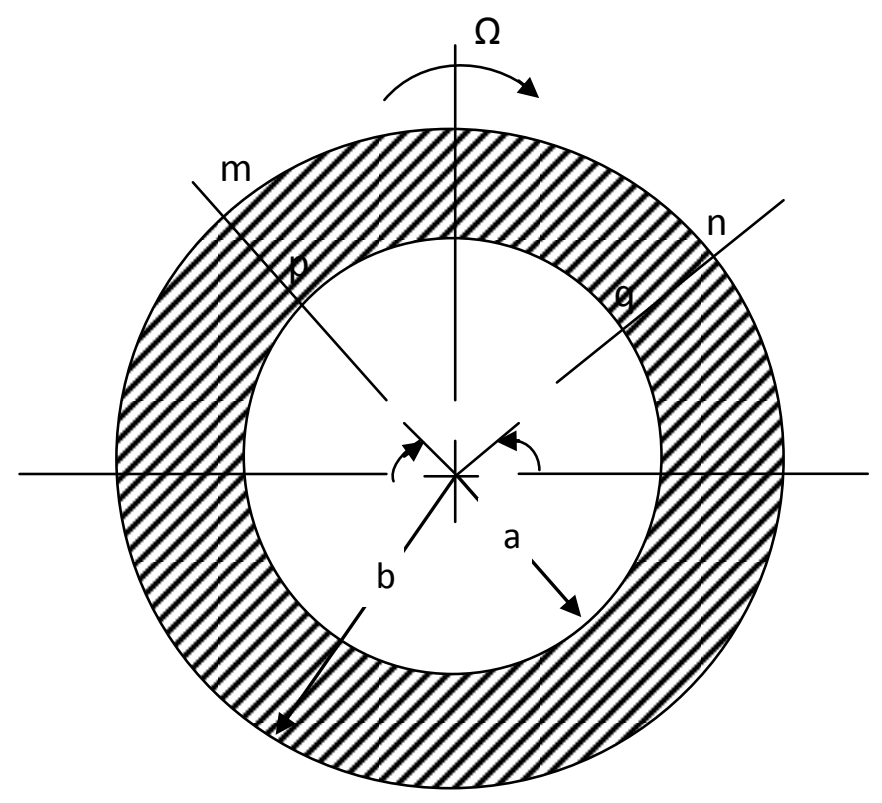

Fig.2. Section of a rotating shaft.

Here it is considered that the rotation of the drill string of a drilling riser will induce an axial force on the drilling riser that can be expressed by Eq.(2.14). Therefore, Eq.(2.14) is substituted into Eq.(2.13) to include the effect of the rotation of the drill string on the response of the drilling riser as follows 


$$
E I \frac{\partial^{4} w}{\partial y^{4}}-\mu \frac{\partial^{2} w}{\partial y^{2}}-\beta \frac{\partial w}{\partial y}+m_{w} \frac{\partial^{2} w}{\partial t^{2}}=f_{w s}
$$

where

$$
\mu=T+A_{o} \bar{P}_{o}-A_{i} \bar{P}_{i}-v \rho I_{P} \Omega^{2} ; \quad \beta=\gamma_{s}\left(A_{o}-A_{i}\right)-f_{y s}-A_{o} \gamma_{0}+A_{i} \gamma_{i}
$$

From Eq.(2.15), the effect of the rotation of the drill string on the flexural motion of the drilling riser is introduced through the coefficient $\mu$.

\section{Free vibration analysis}

An analytical solution to Eq.(2.15) can be written as

$$
w(y, t)=\sum_{m=1}^{N} W_{m} \sin \left(\frac{m \pi y}{l}\right) f(t)
$$

where $W_{m}$ is the amplitude of the response of the riser, and $f(t)$ is the temporal response of the riser and the modal parameter of interest in this study.

\subsection{Temporal response analysis}

For the free vibration, the excitation force $f_{w s}$ is zero so that Eq.(2.15) becomes

$$
E I \frac{\partial^{4} w}{\partial y^{4}}-\mu \frac{\partial^{2} w}{\partial y^{2}}-\beta \frac{\partial w}{\partial y}+m_{w} \frac{\partial^{2} w}{\partial t^{2}}=0
$$

After substituting the solution into Eq.(3.2) we have

$$
\lambda \ddot{f}(t)+\alpha f(t)=0
$$

where

$$
\begin{aligned}
& \lambda=m_{w} \sum_{m=1}^{N} W_{m} \sin \left(\frac{m \pi y}{l}\right) \text { and } \\
& \alpha=E I \sum_{m=1}^{N}\left(\frac{m \pi}{l}\right)^{4} W_{m} \sin \left(\frac{m \pi y}{l}\right)+\mu \sum_{m=1}^{N}\left(\frac{m \pi}{l}\right)^{2} W_{m} \sin \left(\frac{m \pi y}{l}\right)+ \\
& -\beta \sum_{m=1}^{N}\left(\frac{m \pi}{l}\right) W_{m} \cos \left(\frac{m \pi y}{l}\right) .
\end{aligned}
$$

For the fundamental mode $(m=1)$ and at mid-span $(y=l / 2)$

$$
\lambda=m_{w} W_{l} \quad \text { and } \quad \alpha=\left[E I\left(\frac{\pi}{l}\right)^{4}+\mu\left(\frac{\pi}{l}\right)^{2}\right] W_{l} .
$$




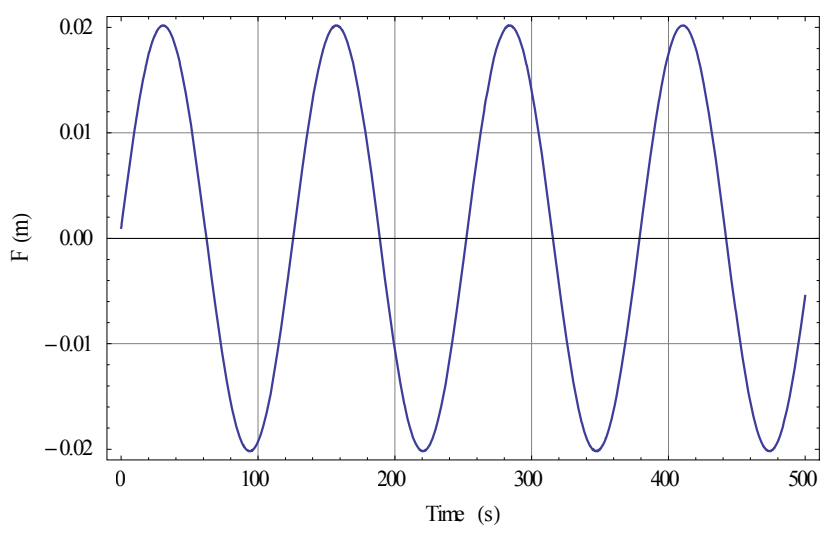

(a) Amplitude $=0.201792 \mathrm{~m}$

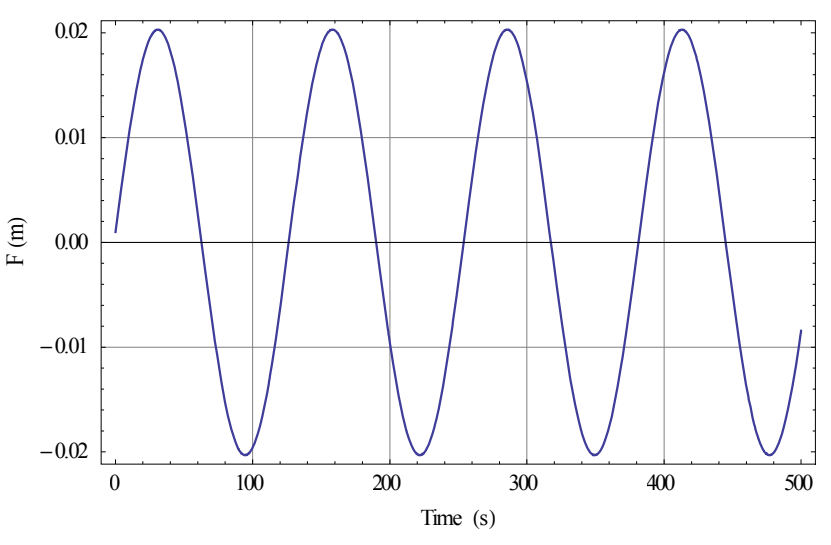

(b) Amplitude $=0.203042 \mathrm{~m}$

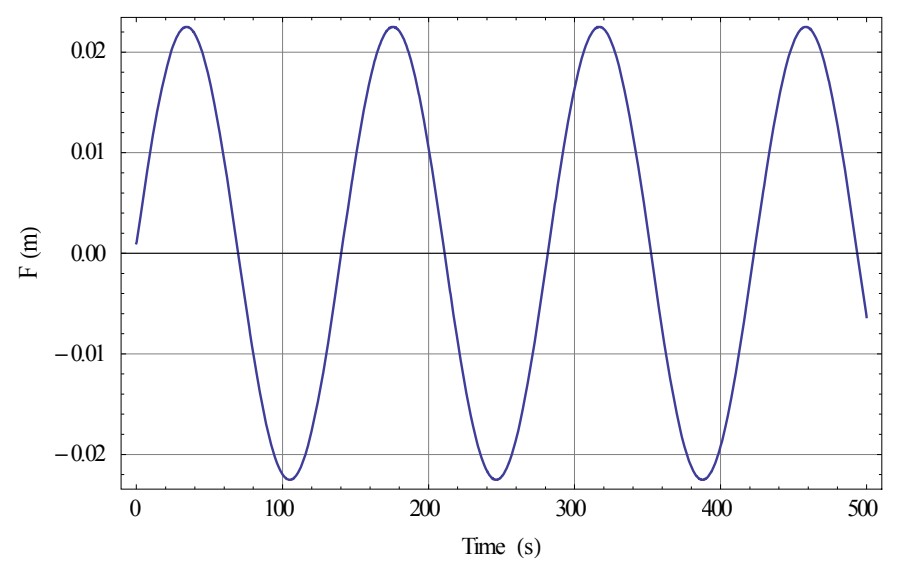

(c) Amplitude $=0.0225128 \mathrm{~m}$

Fig.1. Time-domain response of the drilling riser for (a) $0 \mathrm{rev} / \mathrm{min}$ (b) $500 \mathrm{rev} / \mathrm{min}$ (c) $2000 \mathrm{rev} / \mathrm{min}$.

\subsection{Natural frequencies}

Assuming $f(t)$ is a sinusoidal function, then the solution can be written as

$$
w(y, t)=\sum_{m=1}^{N} W_{m} \sin \left(\frac{m \pi y}{l}\right) e^{i \omega_{n} t}
$$

where $\omega_{n}$ is the natural frequency of the riser.

Substituting Eq.(3.4) into Eq.(3.2) we arrive at

$$
\begin{aligned}
& \sum_{m=1}^{N} W_{m}\left[E I\left(\frac{m \pi}{l}\right)^{4} \sin \left(\frac{m \pi y}{l}\right)+\mu\left(\frac{m \pi}{l}\right)^{2} \sin \left(\frac{m \pi y}{l}\right)+\right. \\
& \left.-\beta\left(\frac{m \pi}{l}\right) \cos \left(\frac{m \pi y}{l}\right)-m_{w} \omega_{n}^{2} \sin \left(\frac{m \pi y}{l}\right)\right]=0 .
\end{aligned}
$$


To solve Eq.(3.5), we multiply through by $\sin \left(\frac{m \pi y}{l}\right)$ and integrate over the span of the riser. When this is done, we arrive at the following equation.

$$
\sum_{m=1}^{N} A_{m}\left[E I\left(\frac{m \pi}{l}\right)^{4}+\mu\left(\frac{m \pi}{l}\right)^{2}-m_{w} \omega_{n}^{2}\right]=0
$$

Equation (3.6) is the characteristic or frequency equation and can be used to obtain the natural frequency of the $m^{\text {th }}$ mode of vibration of the riser as shown in Eq.(3.7).

$$
\omega_{n}^{2}=\frac{1}{m_{w}}\left[E I\left(\frac{m \pi}{l}\right)^{4}+\mu\left(\frac{m \pi}{l}\right)^{2}\right] .
$$

\section{Results and discussion}

The natural frequencies for the first ten modes of vibration for different lengths of the drilling riser are shown Tab.1.

Table $1(\mathrm{a}-\mathrm{c})$. Natural frequencies of the drilling riser for different rotational speeds of the drill string.

\begin{tabular}{|c|c|c|c|c|c|c|c|}
\hline \multicolumn{2}{|c|}{$\begin{array}{c}\text { Rotational } \\
\text { speed } \\
\text { (rev/min) }\end{array}$} & $\mathbf{\Omega}=\mathbf{0}$ & $\Omega=100$ & $\Omega=200$ & $\Omega=300$ & $\Omega=400$ & $\Omega=500$ \\
\hline \multirow{10}{*}{ 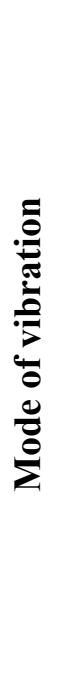 } & 1 & 0.0994976 & 0.0994428 & 0.0992781 & 0.099003 & 0.0986165 & 0.0981174 \\
\hline & 2 & 0.262348 & 0.262265 & 0.262015 & 0.261598 & 0.261014 & 0.26026 \\
\hline & 3 & 0.514259 & 0.514164 & 0.513877 & 0.513399 & 0.512729 & 0.511867 \\
\hline & 4 & 0.861942 & 0.861841 & 0.861537 & 0.861031 & 0.860321 & 0.859407 \\
\hline & 5 & 1.30724 & 1.30713 & 1.30682 & 1.3063 & 1.30557 & 1.30462 \\
\hline & 6 & 1.85075 & 1.85064 & 1.85032 & 1.84979 & 1.84905 & 1.84809 \\
\hline & 7 & 2.49272 & 2.49261 & 2.49229 & 2.49176 & 2.49101 & 2.49004 \\
\hline & 8 & 3.23326 & 3.23316 & 3.23283 & 3.23229 & 3.23154 & 3.23056 \\
\hline & 9 & 4.07243 & 4.07232 & 4.072 & 4.07145 & 4.07069 & 4.06972 \\
\hline & 10 & 5.01025 & 5.01014 & 5.00981 & 5.00927 & 5.00851 & 5.00753 \\
\hline
\end{tabular}

(a) Riser length $=500 \mathrm{~m}$. 
(b) Riser length $=1000 \mathrm{~m}$.

\begin{tabular}{|c|c|c|c|c|c|c|c|}
\hline \multicolumn{2}{|c|}{$\begin{array}{l}\text { Rotational } \\
\text { speed } \\
\text { (rev/min) }\end{array}$} & $\Omega=0$ & $\Omega=100$ & $\Omega=200$ & $\Omega=300$ & $\Omega=400$ & $\mathbf{\Omega}=500$ \\
\hline \multirow{10}{*}{ 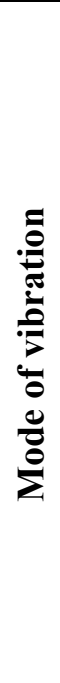 } & 1 & 0.0618142 & 0.0617922 & 0.0617259 & 0.0616154 & 0.0614602 & 0.0612602 \\
\hline & 2 & 0.130808 & 0.130766 & 0.130641 & 0.130432 & 0.130139 & 0.129761 \\
\hline & 3 & 0.212954 & 0.212896 & 0.212723 & 0.212434 & 0.212029 & 0.211508 \\
\hline & 4 & 0.312522 & 0.312453 & 0.312243 & 0.311893 & 0.311403 & 0.310772 \\
\hline & 5 & 0.432274 & 0.432195 & 0.431958 & 0.431563 & 0.43101 & 0.430297 \\
\hline & 6 & 0.5739 & 0.573814 & 0.573557 & 0.573129 & 0.572529 & 0.571757 \\
\hline & 7 & 0.73842 & 0.73833 & 0.738058 & 0.737605 & 0.736971 & 0.736155 \\
\hline & 8 & 0.926455 & 0.926361 & 0.926078 & 0.925607 & 0.924947 & 0.924097 \\
\hline & 9 & 1.13839 & 1.13829 & 1.138 & 1.13751 & 1.13683 & 1.13596 \\
\hline & 10 & 1.37446 & 1.37436 & 1.37406 & 1.37357 & 1.37287 & 1.37198 \\
\hline
\end{tabular}

(c) Riser length $=1500 \mathrm{~m}$.

\begin{tabular}{|c|c|c|c|c|c|c|c|}
\hline \multicolumn{2}{|c|}{\begin{tabular}{|c|} 
Rotational \\
speed \\
(rev/min)
\end{tabular}} & $\mathbf{\Omega}=\mathbf{0}$ & $\Omega=100$ & $\Omega=200$ & $\Omega=300$ & $\Omega=400$ & $\Omega=500$ \\
\hline \multirow{10}{*}{ 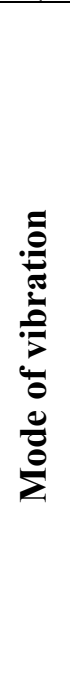 } & 1 & 0.049617 & 0.0496048 & 0.0495681 & 0.049507 & 0.0494212 & 0.0493107 \\
\hline & 2 & 0.101036 & 0.101012 & 0.10094 & 0.10082 & 0.100651 & 0.100434 \\
\hline & 3 & 0.155954 & 0.155919 & 0.155814 & 0.155639 & 0.155393 & 0.155077 \\
\hline & 4 & 0.215885 & 0.21584 & 0.215705 & 0.21548 & 0.215165 & 0.214759 \\
\hline & 5 & 0.282113 & 0.282059 & 0.281898 & 0.281629 & 0.281252 & 0.280767 \\
\hline & 6 & 0.355688 & 0.355627 & 0.355443 & 0.355135 & 0.354705 & 0.354151 \\
\hline & 7 & 0.43744 & 0.437372 & 0.437168 & 0.436829 & 0.436352 & 0.435739 \\
\hline & 8 & 0.528013 & 0.52794 & 0.527719 & 0.527352 & 0.526836 & 0.526173 \\
\hline & 9 & 0.627901 & 0.627822 & 0.627588 & 0.627197 & 0.626648 & 0.625943 \\
\hline & 10 & 0.737476 & 0.737394 & 0.737148 & 0.736736 & 0.73616 & 0.735419 \\
\hline
\end{tabular}

Numerical results were simulated from Mathematica ${ }^{\mathrm{TM}}$ codes using the input values in Tab.2. Tables 1(a) - (c) show the natural frequencies of the drilling riser for different rotational speeds of the drill string. The second column in these tables represents the natural frequency without the rotation of the drill string. The results reveal that the rotation of the drill string reduces the stiffness of the drilling riser and by extension its natural frequency. 
Table 2. Properties and input parameters of model riser and waves.

\begin{tabular}{|c|l|c|c|c|}
\hline S/No & \multicolumn{1}{|c|}{ Quantity } & Symbol & S.I. Units & Value \\
\hline 1 & Top tension & $T_{l}$ & $N$ & 3000 \\
\hline 2 & Riser length & $L$ & $m$ & 1500 \\
\hline 3 & Density of steel & $\rho_{s}$ & $\mathrm{Kg} / \mathrm{m}^{3}$ & 7850 \\
\hline 4 & Density of water & $\rho_{w}$ & $\mathrm{Kg} / \mathrm{m}^{3}$ & 1000 \\
\hline 5 & Density of mud & $\rho_{m}$ & $\mathrm{Kg} / \mathrm{m}^{3}$ & 1410 \\
\hline 6 & Outer diameter of riser & $d_{o}$ & $\mathrm{~m}$ & 0.3934 \\
\hline 7 & Inner diameter of riser & $d_{i}$ & $m$ & 0.2809 \\
\hline 8 & Outer diameter of drill string & $b$ & $m$ & 0.1683 \\
\hline 9 & Inner diameter of drill string & $a$ & $\mathrm{~N} / \mathrm{m}$ & 0.1483 \\
\hline 10 & Modulus of elasticity & $E$ & $\mathrm{GN} / \mathrm{m}^{2}$ & 210 \\
\hline 11 & Drag coefficient & $C_{D}$ & - & 0.7 \\
\hline 12 & Coefficient of added mass & $C_{m}$ & - & 1.0 \\
\hline
\end{tabular}

Figures 2(a) - (e) are plots showing the variation of the natural frequency of the drilling riser with rotational speed of the drill string. For each mode of vibration, the plots reveal a rotational speed at which the natural frequency of the drilling riser is theoretically zero. The value of the critical rotational speed hereafter referred to as the threshold rotational speed, increases with increasing mode of vibration and can be determined from the following expression

$$
\Omega_{\text {thres }}=\sqrt{\frac{1}{\rho v I_{P}}\left[E I\left(\frac{m \pi}{l}\right)^{2}+T+A_{o} \bar{P}_{o}-A_{i} \bar{P}_{i}\right]}
$$

where $\Omega_{\text {thres }}$ is the threshold rotational speed of the drill string.

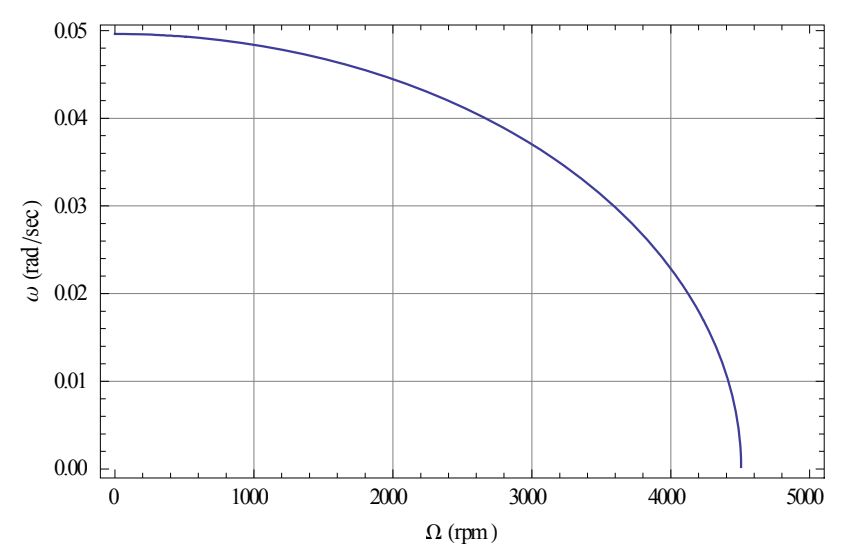

(a) Mode 1

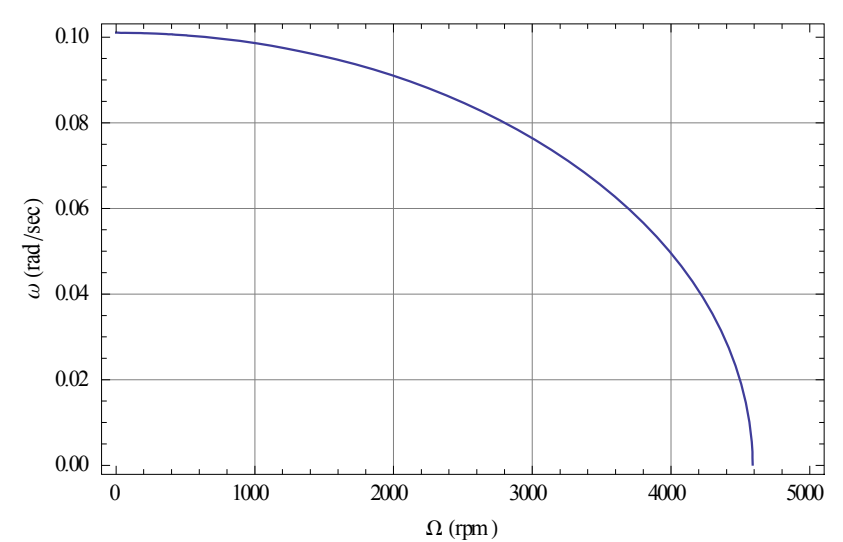

(b) Mode 2 


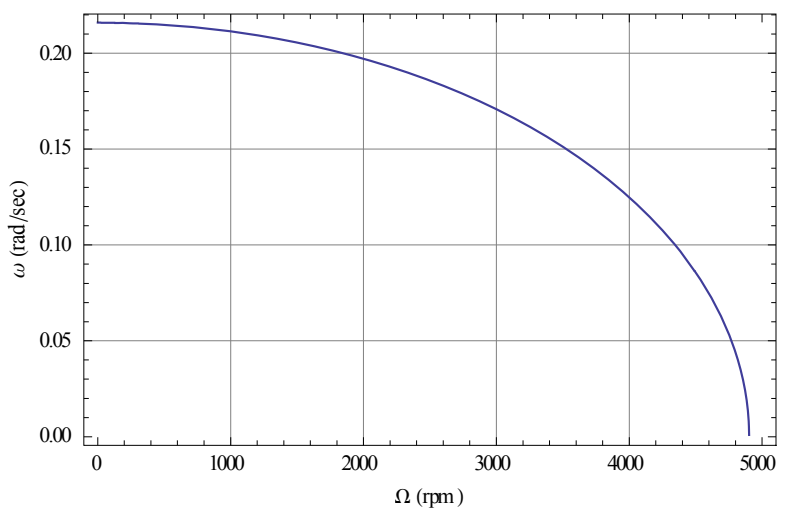

(c) Mode 3

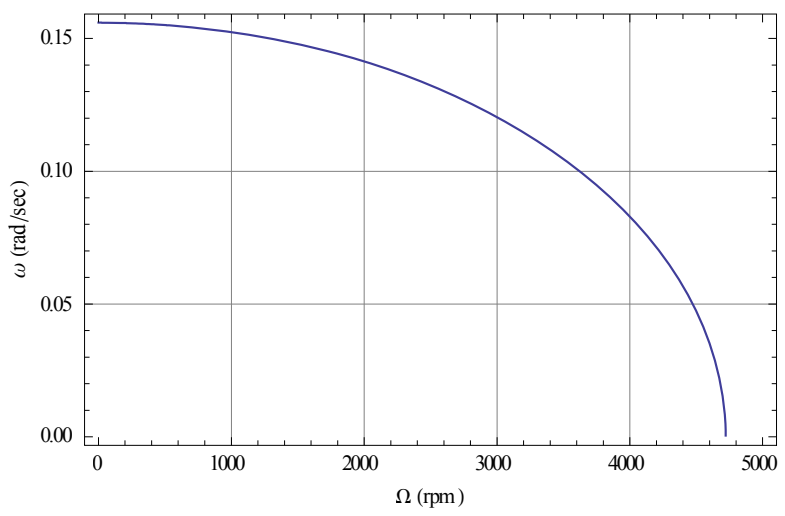

(d) Mode 4

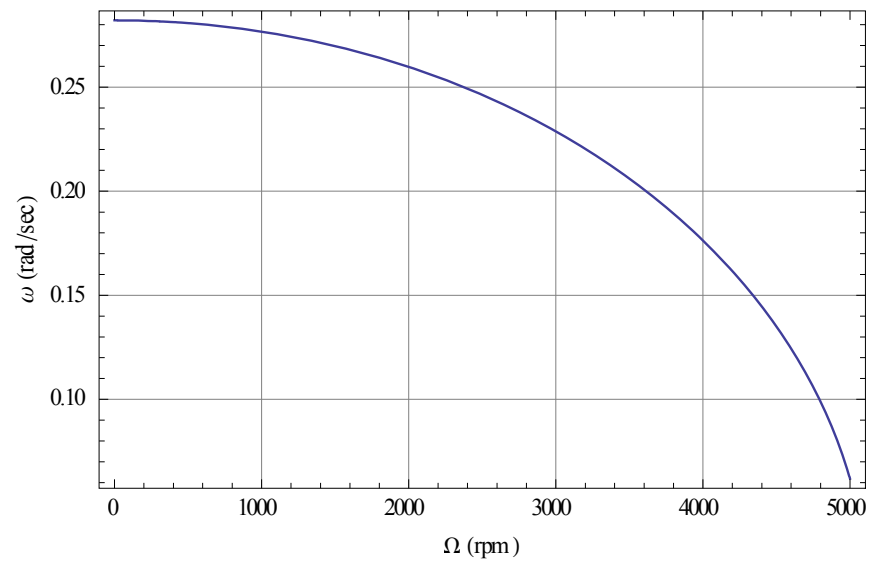

(e) Mode 5

Fig.2. Variation of riser natural frequency with drill string rotational speed for different modes of vibration.

The physical significance of this is that there is a threshold rotational speed of the drill string for a given drilling riser configuration, at which there is no meaningful response of the drilling riser. Although the values of the threshold rotational speed as shown in Figs 2(a) - (e) are well beyond practical drilling speed range (i.e., less than $200 \mathrm{rev} / \mathrm{min}$ ), the existence of such a phenomenon is noteworthy. Additionally, it can be inferred that before reaching the threshold rotational speed, the drill string would have failed in operation.

The time-domain responses for drill string rotational speeds of $0 \mathrm{rev} / \mathrm{min}, 500 \mathrm{rev} / \mathrm{min}$, and 2000 $\mathrm{rev} / \mathrm{min}$ are shown in Figs 1(a) - (c) respectively. It was assumed that the initial displacement and velocity of the riser are very small, and so, the initial conditions used were $1 \mathrm{~mm}$ and $1 \mathrm{~mm} / \mathrm{s}$ respectively. The timedomain responses are all sinusoidal as is expected for an undamped free vibration. The amplitude of the temporal responses reveals that the rotation of the drill string increases the maximum displacement of the riser. The plots in Figs 3(a) - (c) corroborate this observation. Additionally, the plots in Figs 3(a) - (c) reveal that for the same rotational speed of the drill string, the amplitude of vibration reduces with increasing mode of vibration. This can be explained by the fact that the riser becomes stiffer at higher modes and therefore offers a better resistance to displacements. 


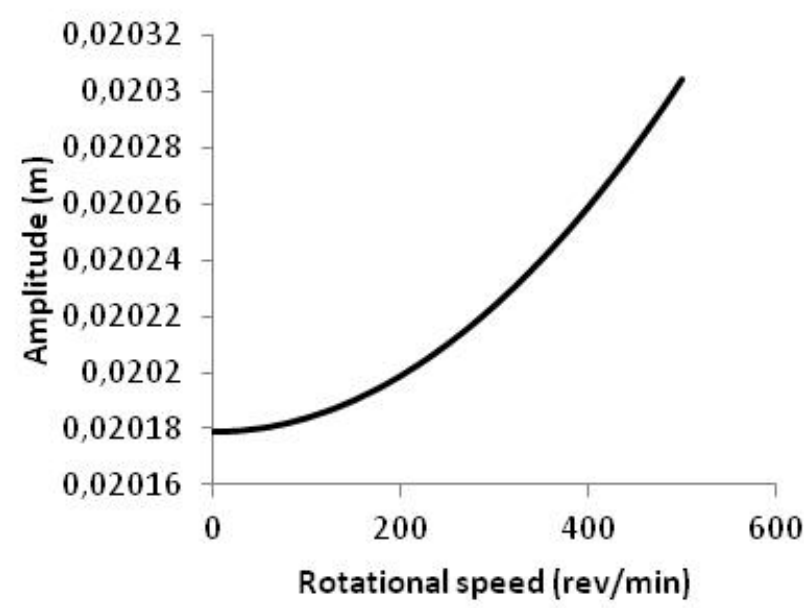

(a) Mode 1

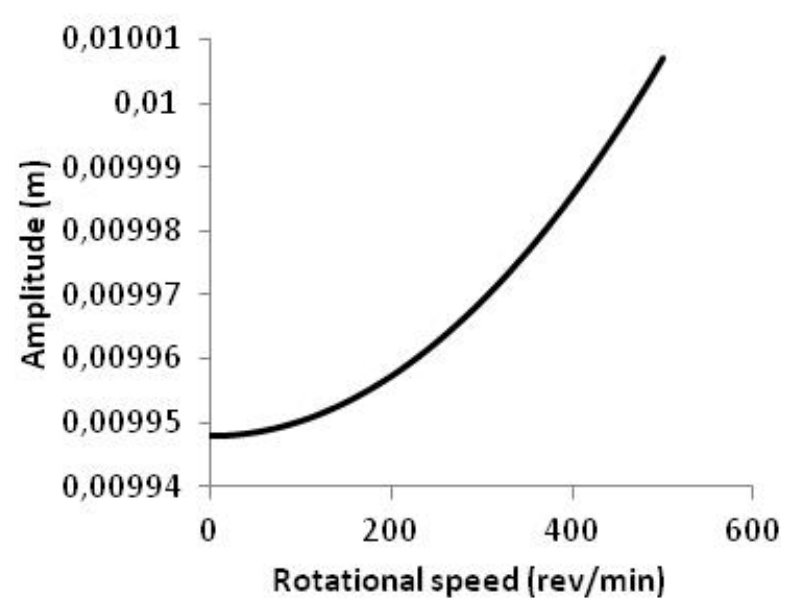

(b) Mode 2

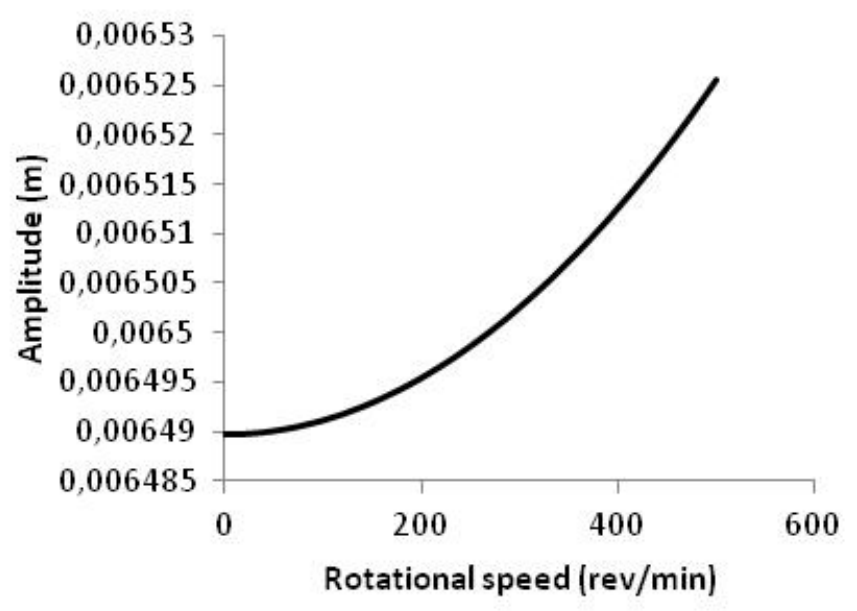

(c) Mode 3

Fig.3. Time-domain response amplitude versus drill string rotational speed for different modes of vibration.

\section{Conclusion}

The effect of the rotational speed of the drill string of a drilling riser on the free vibration of the drilling riser has been investigated in this paper. The rotation of the drill string induces an axial force on the riser, which affects its response. This concept has been incorporated in developing the governing equation of the drilling riser, and the resulting differential equation has a variable coefficient, which is a function of the drill string rotational speed. The governing equation was solved, and results were simulated for the natural frequencies and temporal displacements by means of bespoke Mathematica ${ }^{\mathrm{TM}}$ codes. The results reveal that the effect of the rotation of the drill string is to reduce the natural frequency and increase the amplitude of vibration of the riser. The implication of these findings is that neglecting the effect of rotation of the drill string leads to under-estimation of the deflection and over-estimation of the natural frequency. It was also discovered that for a drilling riser with given dimensions, there exists a 
rotational speed of the drill string at which the natural frequency of the riser is theoretically zero. This rotational speed has been referred to as the threshold rotational speed of the drill string. In the present simulations, the threshold rotational speeds for different modes of vibration were found to be way beyond practical drilling speeds. This study shows that the dynamics of a drilling riser during production is significantly different from that of general risers because of the rotation of the drill string, which influences the behaviour of the drilling riser.

\section{Nomenclature}

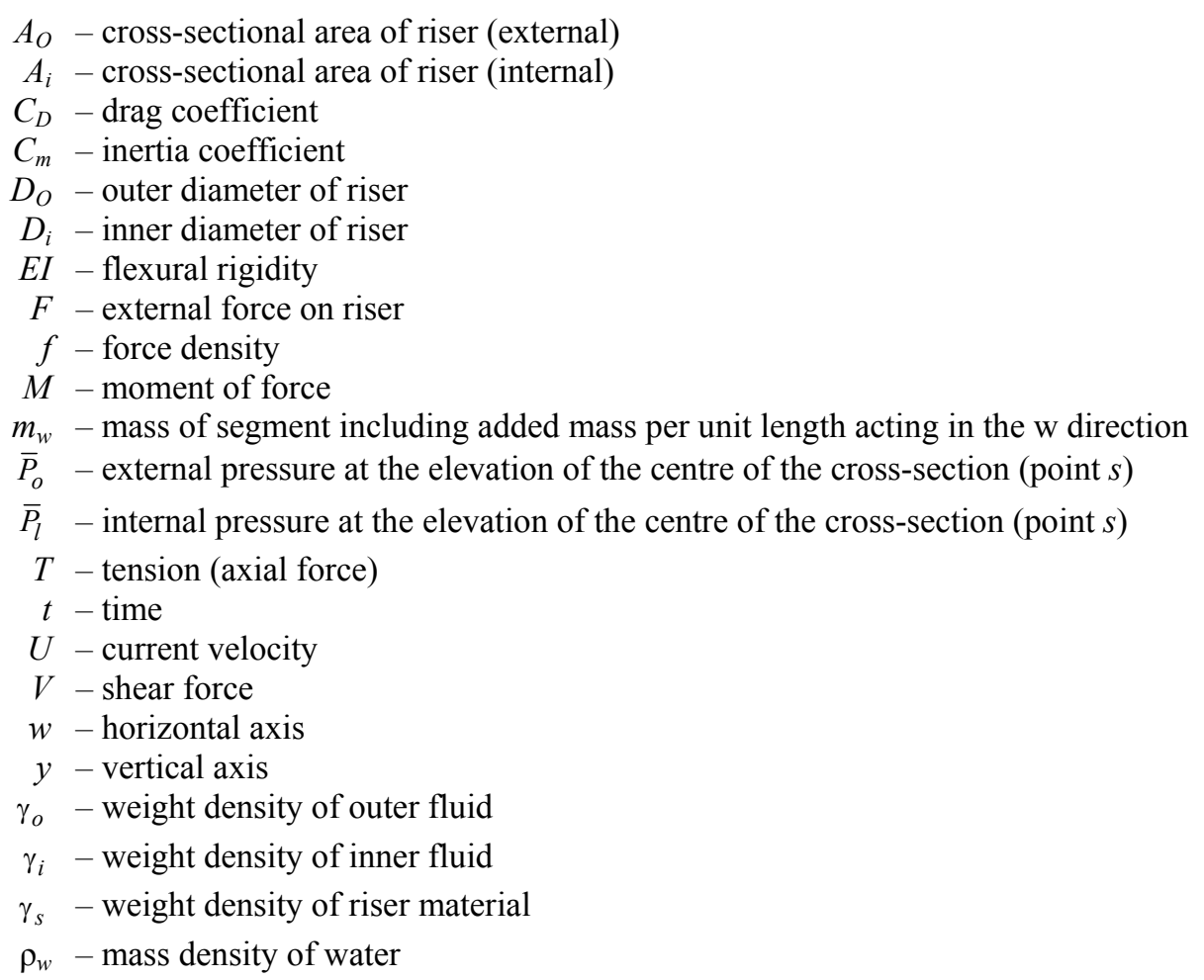

\section{References}

Behzad M. and Bastami A.R. (2004): Effect of centrifugal force on natural frequency of lateral vibration of rotating shafts. - Journal of Sound and Vibration, vol.274, pp.985-995.

Chakrabarti S.K. and Frampton R.E. (1982): Review of riser analysis techniques. - Applied Ocean Research, vol.4, No.2, pp.73-90.

Chen Y., Chai Y.H., Li X. and Zhou J. (2009): An extraction of the natural frequencies and mode shapes of marine risers by the method of differential transformation. - Computers and Structures, vol.87, pp.1384-1393.

Ghadimi R. (1988): A simple and efficient algorithm for the static and dynamic analysis of flexible marine risers. Computers and Structures, vol.29, No.4, pp.541-555.

Gulyayev V.I. and Borshch O.I. (2011): Free vibrations of drill strings in hyper deep vertical bore-wells. - Journal of Petroleum Sciences and Engineering, vol.78, pp.759-764.

Gulyayev V.I., Gaidaichuk V.V., Solovjov I.L. and Gorbunovich I.V. (2009): The buckling of elongated rotating drill strings. - Journal of Petroleum Sciences and Engineering, vol.67, pp.140-148.

Kaewunruen S., Chiravatchradej J. and Chucheepsakul S. (2005): Nonlinear free vibration of marine risers/pipes transporting fluid. - Ocean Engineering, vol.32, pp.417-440. 
Keber M. and Wiercigroch M. (2008): Dynamics of a vertical riser with weak structural nonlinearity excited by wakes. - Journal of Sound and Vibration, vol.315, pp.685-699.

Sampaio R., Piovan M.T. and Venero L.G. (2007): Coupled axial/torsional vibrations of drill-strings by means of nonlinear model. - Mechanics Research Communications, vol.34, pp.497-502.

Spanos P.D., Tein W.Y. and Ghanem R. (1990): Frequency domain analysis of marine risers with time dependent tension. - Applied Ocean Research, vol.12, No.4, pp.200-220.

Vaz M.A. and Patel M.H. (1995): Analysis of drill strings in vertical and deviated holes using the Garlekin technique.Engineering Structures, vol.17, No.6, pp.437-442.

Received: August 2, 2014

Revised: May 20, 2015 